DOI: $10.20472 / E S .2019 .8 .1 .003$

\title{
A NEW STRUCTURAL ANALYSIS OF INFLATION AND ECONOMIC ACTIVITY
}

\author{
JUN GAO, SHENG ZHU
}

\begin{abstract}
:
We theoretically investigate the role of expectations in modelling economic activity and the evolution of inflation rates. The New Keynesian Phillips-IS model is extended in our study by having two types of firms with a fraction of firms that uses 'limited' information to develop their expectations. The remaining firms, which are referred to as forward-looking, would use all information available to set prices and make manufacturing budgets. Then we use UK data to examine the robustness of our extension. To estimate our augmented model, we employ the Uhlig (2005) priori restrictions and the Nakajima (2011a) time-varying parameter regression. Our results suggest that the expectations of each type of firms play an important role in explaining the inflation rate and real economic growth in the UK.
\end{abstract}

\section{Keywords:}

Phillips curve, IS curve, expectations, time-varying parameter regression

JEL Classification: C11, E12, E31

\section{Authors:}

JUN GAO, University College Cork, Ireland, Ireland, Email: jun.gao@ucc.ie

SHENG ZHU, University College Cork, Ireland, Ireland, Email: sheng.zhu@ucc.ie

\section{Citation:}

JUN GAO, SHENG ZHU (2019). A New Structural Analysis of Inflation and Economic Activity. International Journal of Economic Sciences, Vol. VIII(1), pp. 35-51., 10.20472/ES.2019.8.1.003

Acknowledge: We are grateful for financial support from the CBL Research Strategic Development Fund, University College Cork. We thank participants at the 17th Annual European Economics and Finance Society conference for helpful comments and suggestions. 


\section{Introduction}

An important issue in macroeconomics is that inflation and economic activity are well described by two equations respectively, the Phillips curve and the IS curve. However, empirical evidence is mixed in the literature and there is no consensus regarding the structural interpretation of the two-equation model.

We contribute to the existing studies on structural analysis of inflation and economic activity by introducing an augmented Phillips-IS model that nests variants of Phillips and IS equations. Our extension is developed on the assumption that firms attempt to maximise their profits but make pricing and manufacturing decisions based on different sets of information of interest. In order to examine the robustness of our extension, we apply UK macro data and the Nakajima (2011) time-varying parameter regression to our extension. To our best knowledge, we are also the first study using the Monetary Policy Committee's (MPC) inflation projection and its projected output growth rates to examine the role of expectations in the UK economy.

The rest of the paper is organised as follows. In Section 2 we review the existing literature on Phillips-IS models; in Section 3 we describe the methodology used to model, describe and explain the evolution of inflation and economic activity; we report our empirical analysis in Section 4; Section 5 concludes.

\section{Research Background}

The traditional Phillips curve states that inflation $\left(\pi_{t}\right)$ is modelled as a function as its own lag $\left(\pi_{t-1}\right)$ and a measure of excess demand $\left(\bar{y}_{t}\right)$ such as the output gap:

$$
\pi_{t}=a_{1} \bar{y}_{t}+a_{2} \pi_{t-1}+u_{t}
$$

where $u_{t}$ is an error term. The inclusion of lagged inflation could be explained in several different ways. As in Rudd and Whelan (2005), traditionally researchers use the lagged inflation rate, because past inflation is directly incorporated into the current price level and $\pi_{t-1}$ may proxy for inflation expectations $E_{t-1}\left(\pi_{t}\right)$. However, there are some studies (such as, Roberts (1995)) arguing that lagged inflation appears to matter only because it is correlated to the expected inflation rate for the next period and thus the term $u_{t}$ becomes as an expectation error, $u_{t} \equiv \pi_{t}-E_{t-1}\left(\pi_{t}\right)$.

As demonstrated by Roberts (1995), it would be more appropriate to include a forward-looking component and thus should re-write [1] as:

$$
\pi_{t}=a_{1} \bar{y}_{t}+a_{2} E_{t}\left(\pi_{t+1}\right)
$$

where [2] is usually considered as the New Keynesian (NK) Phillips curve in the literature. It is noteworthy that similar to traditional Phillips-curve relationship as in [1], the inflation rate in [2] depends positively on the output gap $\left(\bar{y}_{t}\right)$ and the impact of inflation expectations $\left(E_{t}\left(\pi_{t+1}\right)\right)$. In contrast to [1], the NK Phillips curve indicates that it is $E_{t}\left(\pi_{t+1}\right)$ rather than $E_{t-1}\left(\pi_{t}\right)$ (previously proxied by $\pi_{t-1}$ in [1]) that matters. 
Gali and Gertler (1999) highlight a discomforting feature of the new Phillips curve [2] that there is no short-run trade-off between output and inflation rates. As they have shown, iterating [2] forward would yield $\pi_{t}=a_{1} \sum_{k=0}^{\infty} d^{k} E_{t}\left(\bar{y}_{t+k}\right)$ where $d$ denotes a subjective discount factor. This means that disinflation can be achieved costlessly and immediately by the central bank that commits to eliminating the future output gap. However, empirical findings in much of the existing literature such as Ball (1994) indicate that disinflation always involves substantial output losses as opposed to the implication of [2]. Therefore, Chadha, Masson and Meredith (1992) and Gali and Gertler (1999) consider a hybrid version of the traditional and the new curves:

$$
\pi_{t}=a_{1} \bar{y}_{t}+a_{2} E_{t}\left(\pi_{t+1}\right)+a_{3} \pi_{t-1}
$$

where the inclusion of lagged inflation captures the inflation persistence that is unexplained in [2]. Ireland (2007) and Meenagh, Minford, Nowell, Sofat and Srinivasan (2009) show persistence in inflation in the United States (US) and UK respectively. [3] is also in line with the findings that disinflation may lead to significant output losses.

Prior to Gali and Gertler (1999), estimation of [3] is almost empirically motivated. Chadha et al. (1992) restrict the sum of $a_{2}$ and $a_{3}$ to equal 1.0 and obtain reasonable parameter estimates of [3] for the US and the Euro Area. Gali and Gertler (1999) theoretically demonstrate the structure of [3] by assuming the co-existence of two types of firms, forward-looking and backward-looking. As in Gali and Gertler (1999), prices newly set in period t $\left(\bar{p}_{t}^{*}\right)$ is jointly determined by the price level set by forward-looking participants $\left(p_{t}^{F}\right)$ and that by backwardlooking ones $\left(p_{t}^{B}\right)$ :

$$
\bar{p}_{t}^{*}=(1-u) p_{t}^{F}+u p_{t}^{B}
$$

They further assume that backward-looking firms would concentrate on the lagged inflation rate $\pi_{t-1}$ and forward-looking firms behave exactly as described by the New Keynesian model [2]. This leads to:

$$
\begin{gathered}
p_{t}^{B}=\bar{p}_{t-1}^{*}+\pi_{t}^{B}=\bar{p}_{t-1}^{*}+\pi_{t-1} \\
p_{t}^{F}=(1-d \theta) \sum_{k=0}^{\infty}(d \theta)^{k} E_{t}\left(\bar{y}_{t+k}\right)
\end{gathered}
$$

where $\theta$ denotes the probability that the aggregate price level is kept unchanged as in Calvo (1983). In other words, each firm has a probability of $1-\theta$ that it may adjust its prices during the period. Under this assumption, the aggregate price level would evolve according to:

$$
p_{t}=\theta p_{t-1}+(1-\theta) \bar{p}_{t}^{*}
$$

Combining [4]-[7] gives the Gali and Gertler (1999) Phillips curve [3] which nests the purely 
forward-looking New Keynesian model [2] as a particular case. Their derivation also indicates that the sum of the coefficients on the expected inflation rate $\left(a_{2}\right)$ and lagged inflation $\left(a_{3}\right)$ is unnecessarily to be 1.0 .

There are, however, several serious problems with the structural interpretation of Gali and Gertler (1999). First, the aggregate price level set by backward-looking firms $\left(p_{t}^{B}\right)$ is assumed to closely track $\bar{p}_{t-1}^{*}$ in [5]. However, it is likely that a firm is unable to tell whether its competitors are backward-looking or forward-looking - which is also agreed by Gali and Gertler (1999, p. 210). This leads to difficult in obtaining the lagged price level set by firms that change prices $\left(\bar{p}_{t-1}^{*}\right)$. Instead it would be more reasonable to let $p_{t}^{B}$ depend on the past price level $p_{t-1}$ (rather than $\bar{p}_{t-1}^{*}$ ) that is observable, with a correction for inflation $\pi_{t}^{B}$. In other words, [5] should be corrected as:

$$
p_{t}^{B}=p_{t-1}+\pi_{t}^{B}
$$

Second, Gali and Gertler (1999) only consider the backward-looking firms that adjust the current price level $\left(p_{t}^{B}\right)$ according to the lagged inflation rate $\left(\pi_{t-1}\right)$ (as in [5]). They fail to take into account the situation that backward-looking price setters may use historical information including inflation lags to develop their own price adjustment $\pi_{t}^{B}$ at each point in time:

$$
\pi_{t}^{B}=f\left(\bar{y}_{t-1}, \pi_{t-1}, E_{t-1}\left(\pi_{t}\right), \ldots\right)
$$

where the term $\pi_{t}^{B}$ nests $\pi_{t-1}$ as a special situation.

Third, the use of [6] presumes that costless disinflation could be achieved among forwardlooking firms. To our best knowledge, there is no empirical or theoretical evidence to support the assumption.

Given the aforementioned potential drawbacks, we opt to further extend [3] by developing a more general Phillips curve that nests [1]-[3] and the Gali and Gertler (1999) interpretation. Our extension also assumes that co-existence of forward-looking and backward-looking firms that is identical to Gali and Gertler (1999). However, we further assume that firms use different types of information of interest to adjust their prices. In other words, backward-looking firms are assumed to adjust prices using all past information (as in [9]) rather than solely concentrating on $\pi_{t-1}$.

While there is extensive and rapidly growing empirical literature on the Phillips curve, there are much fewer studies discussing the IS equation. In the traditional Monetary Transmission Mechanism, monetary policy affects output via the IS curve and then inflation rates via the Phillips curve. As demonstrated by Goodhart and Hofmann (2005a), monetary transmission depends on the strength of link between the policy interest rate $\left(r_{t}\right)$ and the output gap $\left(\bar{y}_{t}\right)$, the size of $b_{1}$ and $b_{2}$.

$$
\bar{y}_{t}=b_{1} r_{t}+b_{2} \bar{y}_{t-1}
$$


where $b_{1}<0$.

The estimation results of [10] are quite distinct in the literature. Rudebusch and Svensson (1999) apply the backward-looking IS equation [10] to the US and the Euro Area and obtain reasonable estimates of $b_{1}$ and $b_{2}$. Nelson (2001) re-estimates [10] but fails to get a significantly negative coefficient on the policy rate $\left(b_{1}\right)$ for both the US and the UK - which is considered as the IS puzzle.

As in Nelson (2001), the IS puzzle may be caused by misspecification of [10] including omission of forward-looking elements. Therefore, Goodhart and Hofmann (2005b) estimate a hybrid IS curve that comprises, in addition to the current policy rate and the lagged output gap, also the current period's expectation of next period's output gap $\left(E_{t}\left(\bar{y}_{t+1}\right)\right)$ :

$$
\bar{y}_{t}=b_{1} r_{t}+b_{2} \bar{y}_{t-1}+b_{3} E_{t}\left(\bar{y}_{t+1}\right)
$$

where $b_{1}<0$. Using the GMM estimator, Goodhart and Hofmann (2005b) obtain significantly positive estimate of $b_{3}$ for Canada, France, Germany, Italy, Japan, the UK and the US. This suggests that expectations of future economic conditions may alter individuals' and firms' spending and investment behaviour which in turn affects current aggregate output. However, their estimated parameter on the real policy rate $r_{t}$ still appears statistically insignificant in most economies investigated except for the US.

In order to address the IS puzzle, Goodhart and Hofmann (2005b) augment [10] by modelling the output gap $\left(\bar{y}_{t}\right)$ as its own lag $\left(\bar{y}_{t-1}\right)$, the lagged US output gap $\left(\Delta \bar{y}_{t-1}^{U S}\right)$ and a group of lagged financial indicators such as interest rates $\left(r_{t-1}\right)$, real exchange rates $\left(\right.$ rex $\left._{t-1}\right)$, growth rates of housing prices $\left(\Delta h p_{t-1}\right)$, share prices $\left(\Delta s p_{t-1}\right)$, real base money $\left(\Delta m_{t-1}^{\text {base }}\right)$ and real broad money $\left(\Delta m_{t-1}^{\text {broad }}\right)$ :

$$
\begin{gathered}
\bar{y}_{t}=b_{1} r_{t-1}+b_{2} r e x_{t-1}+b_{3} \Delta h p_{t-1}+b_{4} \Delta s p_{t-1}+b_{5} \Delta m_{t-1}^{\text {base }}+b_{6} \Delta m_{t-1}^{\text {broad }}+b_{7} \bar{y}_{t-1} \\
+b_{8} \Delta \bar{y}_{t-1}^{U S}
\end{gathered}
$$

where the development of [12] is empirical motivated. Although Goodhart and Hofmann (2005b) consider the estimation coefficients of [12] are consistent with their expectations, they fail to provide any theoretical interpretation for their extensions.

In our study, we propose to continue the assumption that forward-looking and backward-looking market participants co-exist. They are assumed to use different sets of information to make spending and investment budgets. This would lead to a new structural demonstration of the IS equation.

\section{Methodology}

As already mentioned in [7], the Calvo (1983) model states that each firm is able to adjust its price in any period with a probability $1-\theta$ that is independent of the time the price has been fixed. Therefore, the aggregate price level $p_{t}$ evolves according to: 


$$
p_{t}=\theta p_{t-1}+(1-\theta) \bar{p}_{t}^{*}
$$

Gali and Gertler (1999) propose to consider two types of firms with a fraction $1-\omega$ of firms operating in a forward-looking manner and the remaining firm, of measure $\omega$, referred to as backward-looking. Forward-looking firms are assumed by Gali and Gertler (1999) to use all available information for the purpose of forecasting marginal costs, while backward-looking firms use a simple rule of thumb that is based on the recent historical aggregate price behaviour.

Given the rational discussed in the first section, we opt to depart from Gali and Gertler (1999) by assuming that both forward and backward-looking firms attempt to price 'optimally' but may concentrate on different information of interest. The former uses all information available $I_{t}^{p}$ and thus sets prices $\left(p_{t}^{h}\right)$ in the way as suggested by the hybrid Phillips-curve literature.

$$
\pi_{t}^{h}=\sigma_{1} \bar{y}_{t}+\beta_{1} \pi_{t}^{e}+\gamma_{1} \pi_{t-1}
$$

where

$$
\pi_{t}^{h}=p_{t}^{h}-p_{t-1}
$$

and $\bar{y}_{t}$ is the output gap. The term $\pi_{t}^{e}$ denotes consensus estimates of inflation expectations based on the set of information $I_{t}^{p}$.

The remaining firms concentrate on historical information $I_{t-1}^{p}$ and thus have lagged inflation expectations $\left(\pi_{t-1}^{e}\right)$ to set prices $\left(p_{t}^{b}\right)$. This gives:

$$
\pi_{t}^{b}=\sigma_{2} \bar{y}_{t-1}+\beta_{2} \pi_{t-1}^{e}+\gamma_{2} \pi_{t-1}
$$

where

$$
\pi_{t}^{b}=p_{t}^{b}-p_{t-1}
$$

Eq. [16] shares some similarity with Gali and Gertler (1999) who implicitly incorporate information about the future in a backward-looking firm's pricing strategy. As in [5], Gali and Gertler (1999) calculates $p_{t}^{B}$ as the sum of $\pi_{t-1}$ and $\bar{p}_{t-1}^{*}$, while $\bar{p}_{t-1}^{*}$ is partly determined by expectations in period $t$.

As demonstrated by Gali and Gertler (1999), with the two types of firms we can write the index for the prices newly set in period $t\left(\bar{p}_{t}^{*}\right)$ as:

$$
\bar{p}_{t}^{*}=\omega p_{t}^{b}+(1-\omega) p_{t}^{h}
$$

where the fraction of firms which prefer not to change prices is controlled and accounted by the parameter $\theta$ in [13]. 
Substituting [14]-[18] into [13] produces:

$$
\begin{aligned}
p_{t}=\theta p_{t-1}+ & (1-\omega)(1-\theta)\left(\sigma_{1} \bar{y}_{t}+\beta_{1} \pi_{t}^{e}+\gamma_{1} \pi_{t-1}+p_{t-1}\right) \\
& +\omega(1-\theta)\left(\sigma_{2} \bar{y}_{t-1}+\beta_{2} \pi_{t-1}^{e}+\gamma_{2} \pi_{t-1}+p_{t-1}\right)
\end{aligned}
$$

Let [20] denote the inflation rate $\pi_{t}$ at $t$ :

$$
\pi_{t}=p_{t}-p_{t-1}
$$

Organising [19] gives:

$$
\pi_{t}=\delta_{1} \bar{y}_{t}+\delta_{2} \bar{y}_{t-1}+\delta_{3} \pi_{t}^{e}+\delta_{4} \pi_{t-1}^{e}+\delta_{5} \pi_{t-1}
$$

where $\delta_{1}=\sigma_{1}(1-\omega)(1-\theta), \quad \delta_{2}=\sigma_{2} \omega(1-\theta), \delta_{3}=\beta_{1}(1-\omega)(1-\theta), \delta_{4}=\beta_{2} \omega(1-\theta)$ and $\delta_{5}=(1-\theta)\left(\omega \gamma_{2}-\omega \gamma_{1}+\gamma_{1}\right)$. Therefore, our 'new' Phillips curve [21] consists of two inflation expectations, one-period lagged inflation and the output gaps. It nests variants of Phillips-curve relationships including [1]-[3]. It is noteworthy that if both forward and backward-looking firms operate in the manner as suggested by the traditional NK Phillips curve (see, Roberts (1995)), the two parameters $\gamma_{1}$ and $\gamma_{2}$ would turn to zero which reduces [21] to be:

$$
\pi_{t}=\delta_{1} \bar{y}_{t}+\delta_{2} \bar{y}_{t-1}+\delta_{3} \pi_{t}^{e}+\delta_{4} \pi_{t-1}^{e}
$$

However, if the expectation component is disposed in both [14] and [16] (as in Rudd and Whelan (2005)), [21] suggests that the current and lagged output gaps and the past inflation rate jointly provide a good explanation on the movement of current inflation. Therefore, the 'extended' Phillips model could be re-written as:

$$
\pi_{t}=\delta_{1} \bar{y}_{t}+\delta_{2} \bar{y}_{t-1}+\delta_{5} \pi_{t-1}
$$

While considering aggregate economic activity, we decide to follow a similar procedure by having co-existence of both forward and backward-looking firms in the markets. It is assumed that firms are able to adjust their production in each period with a probability $1-\phi$ that is independent of the time output has been fixed. This leads to the evolution of aggregate economic activity as:

$$
P_{t}=\phi P_{t-1}+(1-\phi) \bar{P}_{t}^{*}
$$

where $P_{t}$ denotes the natural logarithm of the real industrial production index.

A fraction $1-\varpi$ of firms is forward-looking and develops their expectations $\left(P_{t}^{e}\right)$ and production budgets $\left(P_{t}^{h}\right)$ using all available information $I_{t}^{y}$. Drawing on the NK literature particularly in the field of the hybrid IS curve (for example, Ireland (2007)), we write the demeaned production 
growth rate of forward-looking firms $\left(\bar{y}_{t}^{h}\right)$ as:

$$
\bar{y}_{t}^{h}=\alpha_{1} r_{t}+\rho_{1} \bar{y}_{t}^{e}+\kappa_{1} \bar{y}_{t-1}
$$

where

$$
\begin{gathered}
y_{t}^{e}=P_{t}^{e}-P_{t} \\
\bar{y}_{t}^{e}=y_{t}^{e}-\bar{y} \\
\bar{y}_{t}^{h}=P_{t}^{h}-P_{t-1}-\bar{y}
\end{gathered}
$$

where $y_{t}^{e}$ denotes the expected growth rate of aggregate output and $\bar{y}$ is the steady state of economic growth. Eq. [23] assumes that output growth of forward-looking firms is affected by monetary policy $r_{t}$, economic growth expectations and lagged economic development.

The remaining firms, of measure $\varpi$, are assumed backward-looking and prefer to focus on past data $I_{t-1}^{y}$. This results in lagged output expectations among this type of firms and hence lags in their expected economic growth. Accordingly, the demeaned production growth rate of backward-looking companies would evolve according to:

$$
\bar{y}_{t}^{b}=\alpha_{2} r_{t-1}+\rho_{2} \bar{y}_{t-1}^{e}+\kappa_{2} \bar{y}_{t-1}
$$

where

$$
\bar{y}_{t}^{b}=P_{t}^{b}-P_{t-1}-\bar{y}
$$

By having the real industrial production index newly set at $t$ as a weighted average of $\bar{P}_{t}^{h}$ and $\bar{P}_{t}^{b}$ we obtain:

$$
\bar{P}_{t}^{*}=\varpi \bar{P}_{t}^{b}+(1-\varpi) \bar{P}_{t}^{h}
$$

Substituting [23], [26]-[29] into [22] gives:

$$
\begin{aligned}
P_{t}=\phi P_{t-1}+ & (1-\varpi)(1-\phi)\left(\alpha_{1} r_{t}+\rho_{1} \bar{y}_{t}^{e}+\kappa_{1} \bar{y}_{t-1}+\bar{y}+P_{t-1}\right) \\
& +\varpi(1-\phi)\left(\alpha_{2} r_{t-1}+\rho_{2} \bar{y}_{t-1}^{e}+\kappa_{2} \bar{y}_{t-1}+\bar{y}+P_{t-1}\right)
\end{aligned}
$$

Let [31] denote the demeaned output growth rate $\bar{y}_{t}$ at $t$ :

$$
\bar{y}_{t}=P_{t}-P_{t-1}-\bar{y}
$$


Organising [30] gives:

$$
\bar{y}_{t}=\zeta_{0}+\zeta_{1} r_{t}+\zeta_{2} r_{t-1}+\zeta_{3} \bar{y}_{t}^{e}+\zeta_{4} \bar{y}_{t-1}^{e}+\zeta_{5} \bar{y}_{t-1}
$$

where $\zeta_{0}=-\phi \bar{y}, \quad \zeta_{1}=\alpha_{1}(1-\varpi)(1-\phi), \quad \zeta_{2}=\alpha_{2} \varpi(1-\phi), \quad \zeta_{3}=\rho_{1}(1-\varpi)(1-\phi), \quad \zeta_{4}=$ $\rho_{2} \varpi(1-\phi)$ and $\zeta_{5}=(1-\phi)\left(\varpi \kappa_{2}-\varpi \kappa_{1}+\kappa_{1}\right)$. It indicates that given the co-existence of the two types of firms, the contemporaneous and lagged output expectations, current and past monetary policy and one lag of output growth should affect economic development jointly. Eq. [32] also highlights the necessity of including a constant term $\zeta_{0}$ in the hybrid IS model.

We present the augmented Phillips-IS model with constant parameters as below:

$$
\begin{gathered}
\pi_{t}=\delta_{1} \bar{y}_{t}+\delta_{2} \bar{y}_{t-1}+\delta_{3} \pi_{t}^{e}+\delta_{4} \pi_{t-1}^{e}+\delta_{5} \pi_{t-1} \\
\bar{y}_{t}=\zeta_{0}+\zeta_{1} r_{t}+\zeta_{2} r_{t-1}+\zeta_{3} \bar{y}_{t}^{e}+\zeta_{4} \bar{y}_{t-1}^{e}+\zeta_{5} \bar{y}_{t-1}
\end{gathered}
$$

However, given the concern that the relationship between macroeconomic indicators are likely to change over time (see, for instance, Primiceri (2005), Nakajima (2011a, 2011b)), we opt to use the Nakajima (2011a) time-varying parameter regression to estimate our extension. In order to appropriately identify structural shocks, we impose 'sign restrictions' on impulse responses based on the assumed effects on inflation and economic activity. It is restricted that

-The aggregate supply shock would raise inflation and lower economic output, and

- The demand shock should increase both the inflation rate and economic growth.

As explained by Arias, Rubio-Ramirez and Waggoner (2014) and Belongia and Ireland (2016), application of priori restriction would not suffice to identify structural disturbances in the classical sense.

Then the time-varying parameter Phillips-IS model is stated as:

$$
\begin{gathered}
\pi_{t}=\delta_{1, t} \bar{y}_{t}+\delta_{2, t} \bar{y}_{t-1}+\delta_{3, t} \pi_{t}^{e}+\delta_{4, t} \pi_{t-1}^{e}+\delta_{5, t} \pi_{t-1}+\tau_{\pi, t} \varrho_{t}^{A S} \\
\bar{y}_{t}=\zeta_{0, t}+\zeta_{1, t} r_{t}+\zeta_{2, t} r_{t-1}+\zeta_{3, t} \bar{y}_{t}^{e}+\zeta_{4, t} \bar{y}_{t-1}^{e}+\zeta_{5, t} \bar{y}_{t-1}+\tau_{y, t} \varrho_{t}^{A D}
\end{gathered}
$$

where $\varrho_{t}^{A S}$ and $\varrho_{t}^{A D}$ denotes structural disturbances to aggregate supply and aggregate demand with $E\left[\varrho_{t}^{A S}\left(\varrho_{t}^{A S}\right)^{\prime}\right]=I$ and $E\left[\varrho_{t}^{A D}\left(\varrho_{t}^{A D}\right)^{\prime}\right]=I$. We assume a random walk process for all the parameters $\Gamma_{t}$ and $\Phi_{t}$ and geometric random walks for $H_{t}$.

$$
\begin{gathered}
\Gamma_{t}=\Gamma_{t-1}+\varepsilon_{\Gamma, t} \\
\Phi_{t}=\Phi_{t-1}+\varepsilon_{\Phi, t}
\end{gathered}
$$




$$
\log T_{t}=\log T_{t-1}+\varepsilon_{T, t}
$$

where $\Gamma_{t}=\left[\delta_{1, t}, \ldots, \delta_{5, t}\right]^{\prime}, \quad \Phi_{t}=\left[\zeta_{0, t}, \zeta_{1, t}, \ldots, \zeta_{5, t}\right]^{\prime}$ and $T_{t}=\left[\tau_{\pi, t}, \tau_{y, t}\right]^{\prime}$. All of the serially uncorrelated innovations are assumed to be jointly normally distributed with:

$$
\left(\begin{array}{c}
H_{t} \\
\varepsilon_{\Gamma, t} \\
\varepsilon_{\Phi, t} \\
\varepsilon_{T, t}
\end{array}\right) \sim N\left(0,\left(\begin{array}{cccc}
I & 0 & 0 & 0 \\
0 & \Sigma_{\Gamma} & 0 & 0 \\
0 & 0 & \Sigma_{\Phi} & 0 \\
0 & 0 & 0 & \Sigma_{T}
\end{array}\right)\right)
$$

where the $2 \times 1$ vector $H_{t}=\left[\varrho_{t}^{A S}, \varrho_{t}^{A D}\right]^{\prime}$.

The model [33]-[34] is estimated jointly using the Markov Chain Monte Carlo procedure in the context of the Bayesian inference. Particularly we estimate $\Gamma_{t}$ and $\Phi_{t}$ using ordinary least squares (OLS) applied to [33]-[34] and calculate $T_{t}$ by applying the same Cholesky factorisation to the covariance matrix of OLS residuals. The reader is referred to Belongia and Ireland (2016) for a detailed discussion on this strategy of setting priors and Nakajima (2011a) for the algorithm of the time-varying parameter regression with stochastic volatility.

To estimate [33], we employ the period 1997:III-2004:IV as a training sample and produce timevarying parameters for 2005:I-2017:II. Since the policy interest rate was lowered by the Bank to the effective lower bound in 2009:II, we have to estimate the extended IS curve for a shorter period running from 1997:III to 2009:II. Given the concern that the use of training sample for calibrating priors would further reduce the number of observations in our estimation, we opt to apply the full sample period 1997:III-2009:II to calculate priors. Starting from the estimated priors, the same period is fed to draw time-varying parameters from their conditional posterior distributions. In other words, the priors for [33] are obtained based on a pre-sample period, while those for [34] are developed according to in-sample observations. To generate useful posterior estimates, we draw 50,000 samples after the initial 100,000 samples are discarded. For each individual parameter, the inefficiency factors (IF), that is the inverse of the Geweke (1992) Convergence Diagnostics, is employed to examine whether the burn-in period is sufficiently long for the Markov chain to converge in the estimation.

$$
\text { In }=1+2 \sum_{k=1}^{\infty} a u_{k}
$$

where $a u_{k}$ is the $\mathrm{k}$-th autocorrelation of the chain. 


\section{Table 1: Inefficiency Factors}

The extended Phillips and IS curves are estimated by the time-varying parameter regression (with stochastic volatility). To implement the time-varying parameter regression, we use the Markov Chain Monte Carlo procedure in the context of the Bayesian inference. This table reports critical statistical tests of the time-varying parameter regression, i.e., inefficiency factors. According to Primiceri (2005), inefficiency factors for parameters and volatilities around or even below 20 are regarded as quite satisfactory.

Median Mean Minimum Maximum 10th Percentile 90th Percentile

Panel A. The extended Phillips curve

$\begin{array}{lrrrrrr}\text { Coefficients } & 1.3302 & 3.0848 & 1.0687 & 11.2149 & 1.152 & 7.6029 \\ \text { Volatilities } & 7.7649 & 8.7274 & 4.5584 & 19.5594 & 5.7906 & 14.1898\end{array}$

Panel B. The extended IS curve

\begin{tabular}{lrrrrrr} 
Coefficients & 1.493 & 2.7553 & 1.055 & 7.8716 & 1.0628 & 6.701 \\
Volatilities & 7.3058 & 9.3052 & 5.1059 & 23.357 & 6.5251 & 20.6369 \\
\hline
\end{tabular}

(Data source: authors' analysis)

Table 1 reports the inefficiency statistics for estimating the extended Phillips-IS model. Except for a few cases, the IFs are well below 20 . They are remarkably low for time-varying parameters $\left(\Gamma_{t}\right.$ and $\left.\Phi_{t}\right)$. Although the maximum IF for stochastic volatility of an IS curve is around 23.36, roughly $90 \%$ of IFs are below 20.6. As suggested by Primiceri (2005, Appendix B), inefficiency factors for parameters and volatilities around or even below 20 are regarded as quite satisfactory. Therefore, we conclude that the convergence diagnostics seem acceptable.

\section{Data and Results}

In this section, we present empirical findings for the extended Phillips-IS model with time-varying parameters. The purpose is to examine whether our extension in Section 2 is justified by data in the UK. To measure expectations of inflation and output growth, we use the Monetary Policy Committee's (MPC) central projections for inflation and real GDP growth (Source: Inflation Reports of the MPC, Bank of England). The MPC's forecasts are published quarterly in the form of charts showing median projections which represent the Bank's best collective judgement of future inflation and economic developments under the condition that current monetary policy does not change. Our sample period runs from the third quarter of 1997 since which the MPC 
started reporting its projections for GDP growth and ends in the second quarter of 2017. We use the three-month Treasury bills discounted rate (Treas $3 \mathrm{~m}$, Source: Bank of England Interactive Database) to account for the influence of monetary policy in the IS curve [34]. As already mentioned, because the policy interest rate is reduced to the lower bound of $0.5 \%$ in April 2009, we restrict the estimation of [34] to the shorter period 1997:III-2009:II. To measure the movement of inflation $\left(\pi_{t}\right)$ and output growth $\left(y_{t}\right)$ we use the growth rate of the Consumer Price Index and that of real GDP (Sources: Office for National Statistics).

The results are presented in Figure 1-4. Each panel plots the median (thin line) and 30th and 70th percentiles (dash) of the posterior distribution of the indicated coefficients.

\section{Figure 1: The Impact of Expected and Lagged Inflation Rates on the Evolution of Inflation Rates}
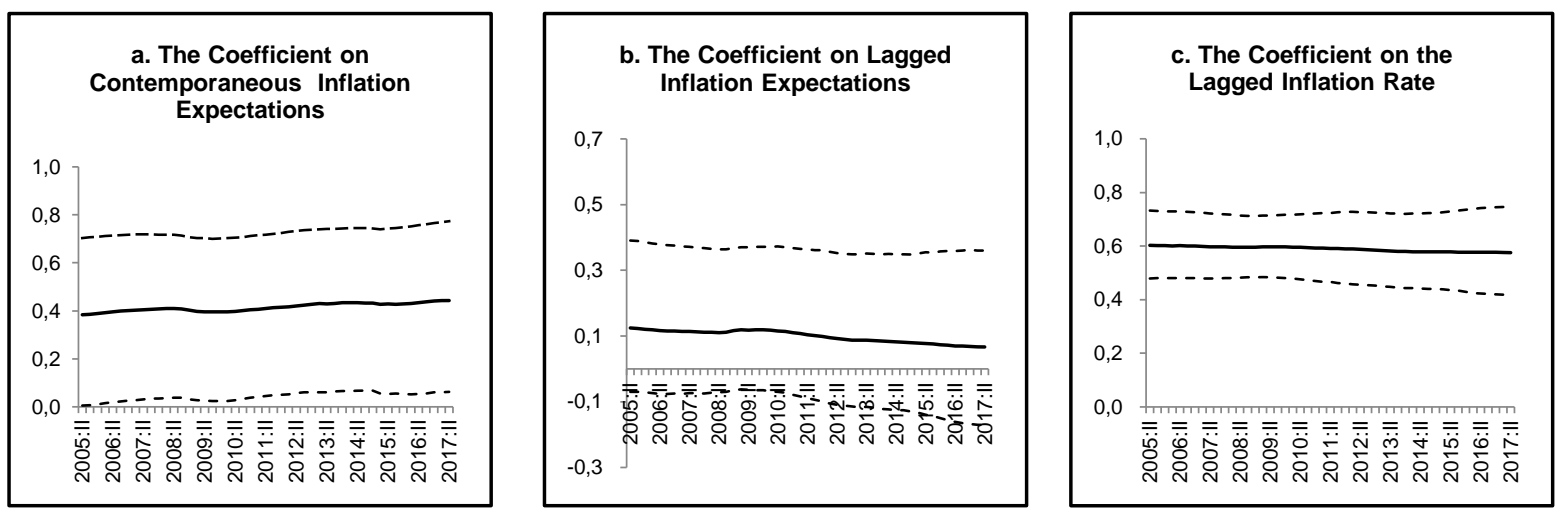

(Data source: authors' analysis)

Figure $1 \mathrm{a}$ and $1 \mathrm{~b}$ track the evolution of the coefficients $\delta_{3, t}$ and $\delta_{4, t}$ (in [33]), which illustrate how expectations affect the current inflation rate. The medians of the posterior distributions of $\delta_{3, t}$ and $\delta_{4, t}$ are both significant throughout the sample period 2005:II-2017:II. This justifies the inclusion of two types of firms that develop expectations and set prices based on different information sets of interest. However, it is noteworthy that as compared to $\delta_{4, t}$, the coefficient $\delta_{3, t}$ looks more stable over the past 12 years. It indicates that at each point in time a onepercentage increase in contemporaneous inflation expectations would lead the inflation rate to rise by roughly 40 basis points and vice versa. This is because firms intend to set prices of their outputs to offset the negative impact of inflation on costs of sales. If raw material costs are expected to rise due to the growing inflation rate, they would set current prices at the higher level to retain their real profits. Furthermore, the declining $\delta_{4, t}$ suggests that recently there are fewer firms that prefer to develop their pricing strategies on the basis of historical information. In other words, market participants are more likely to consider all available information to set prices.

The estimate of the impact parameter $\delta_{5, t}$ (see, Figure 1c) supports the hypothesis that in some cases, some price setters would like to trade-off between output and inflation. They attempt to avoid substantial fluctuations in the output and hence would like to smooth their pricing 
strategies by targeting the past level of inflation. Furthermore, there is less uncertainty surrounding the estimated $\delta_{5, t}$ with narrow bands appearing between the 30th and 70th percentiles of its distribution. Gali and Gertler (1999) and Rudd and Whelan (2005) also obtain the evidence on the significant impact of lagged inflation on the current inflation rate. Therefore, we are confident to conclude that inflation rates should be explained by expected and lagged inflation jointly.

\section{Figure 2: The Short- and Long-run Impacts of Economic Growth on the Evolution of Inflation Rates}
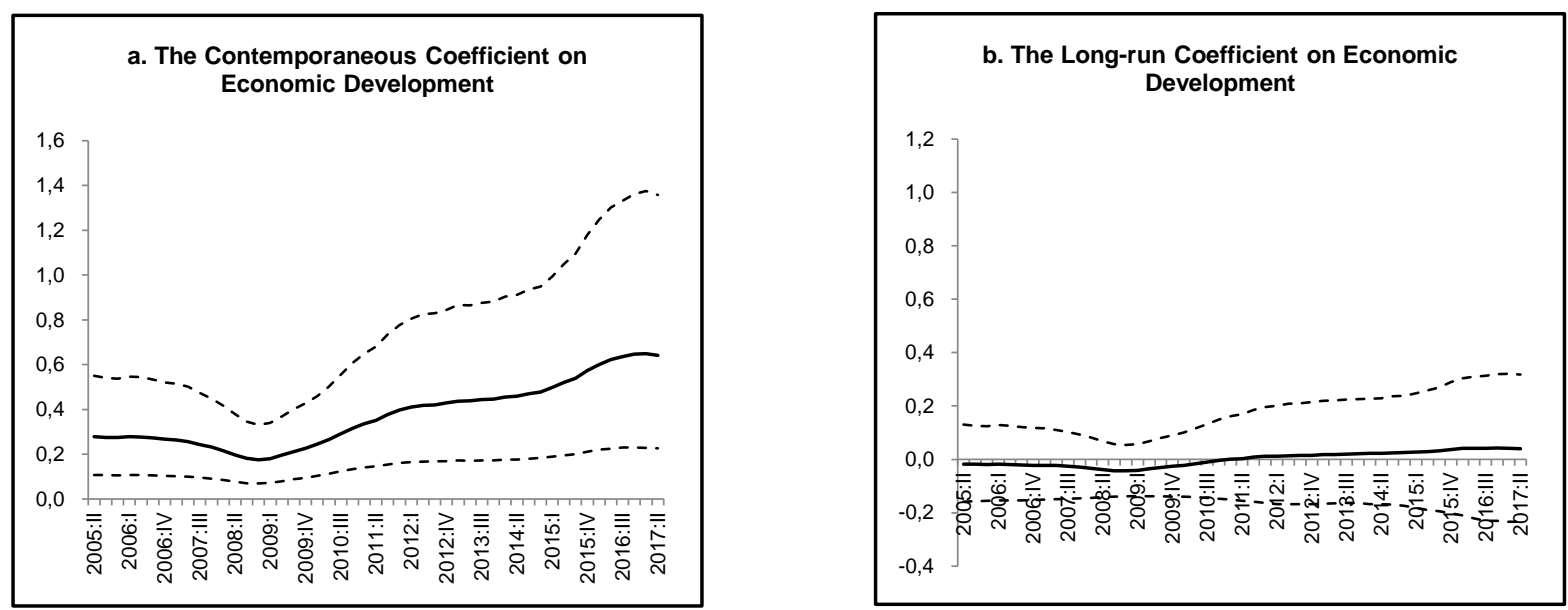

(Data source: authors' analysis)

Turning to the role of economic development in the Phillips curve, we present the contemporaneous and long-run impacts in Figure $2 \mathrm{a}$ and $2 \mathrm{~b}$ respectively. The long-run effect takes into account the influence of the contemporaneous and lagged economic growth $\left(\delta_{1, t}\right.$ and $\left.\delta_{2, t}\right)$ and that of the past inflation rate $\left(\delta_{5, t}\right)$ :

$$
\delta_{t}^{\text {Long-run }}=\left(\delta_{1, t}+\delta_{2, t}\right) /\left(1-\delta_{5, t}\right)
$$

where $\delta_{t}^{\text {Long-run }}$ denotes the long-term coefficient on economic activity. The results imply that although contemporaneous economic growth usually suggests a rise in the inflation rate as explained by the standard monetary transmission mechanism, such a relationship would disappear over the long run. In other words, the upward pressure on inflation, which comes from real economic growth, is likely to be transient. In addition to that, Figure 2a shows that the shortterm relationship between inflation and economic growth has been getting much stronger since the 2008-9 financial crisis. A further look at the Bank's monetary policy from 2009 would provide an explanation to the observed phenomenon. As acknowledged in the MPC's inflation reports (see, for instance, Inflation Reports (August 2009)), the Bank of England increased the scale of its asset purchases financed by the issuance of central bank reserves when the policy interest rate approached the effective zero lower bound in April 2009. Therefore, since the second quarter of 2009 monetary stimulus was brought by the Bank to economy though creating broad money - which is witnessed by the considerable increase in M4 in the UK. Since inflation is 
always and everywhere a monetary phenomenon (see, Friedman (1968, p. 39)), the 'unconventional' monetary instrument would not only lead to improved economic activity but has also resulted in higher inflation during the period and thus increased coefficient $\delta_{1, t}$ in Figure $2 a$.

Figure 3: The Impact of Expected and Lagged Output Gaps on Economic Activity
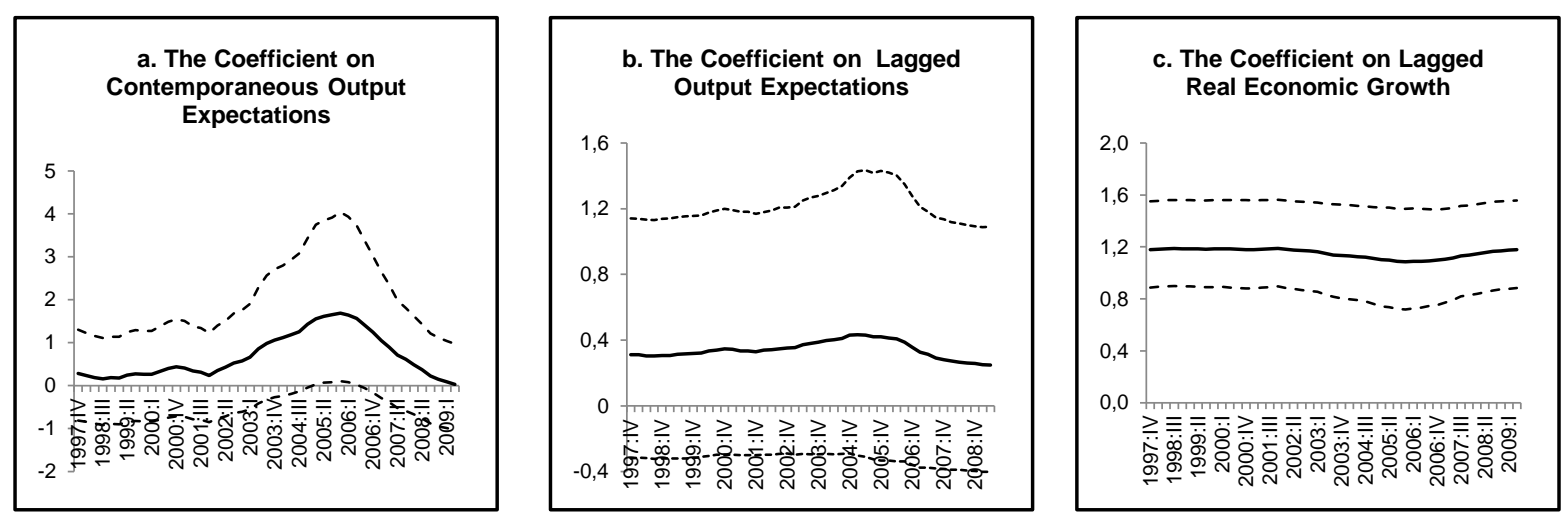

(Data source: authors' analysis)

Figure 3 and 4 focus on the results of estimating [34]. Figure $3 a$ and $3 b$ highlight changes in the role of expectations in the IS curve. However, different from the extended Phillips curve in Figure 1 which suggests that 'forward-looking' firms play a more important role in explaining the inflation rate, Figure 3 shows that the firms that develop expectations and make production plans based on historical information, i.e., the backward-looking market participants, dominate the movement of overall output. Furthermore, there exhibits much variation in Figure 3a which shows that the coefficient $\zeta_{3, t}$ rises prior to the recent economic recession but declines to zero at the end of the sample period. Given the significant estimate of the parameter on lagged economic growth $\left(\zeta_{5, t}\right)$ in Figure $3 \mathrm{c}$, we can infer that when economic growth is perceived as strong and sustainable, firms are more likely to make forecasts on the future demands and take expectations into account while developing production plans. However, they would become conservative when there is much uncertainty in the future economic activity. In that situation, market participants become unwilling to predict future demands on their products in fears of making mistakes and hence would prefer to use the historical level as a guide in their production. This explains why the parameter $\zeta_{5, t}$ falls slightly between 2003 and 2005 (see, Figure 3c) during which $\zeta_{3, t}$ increases dramatically (see, Figure 3a). 


\section{Figure 4: The Short and Long-run Impacts of Monetary Policy on Economic Activity}

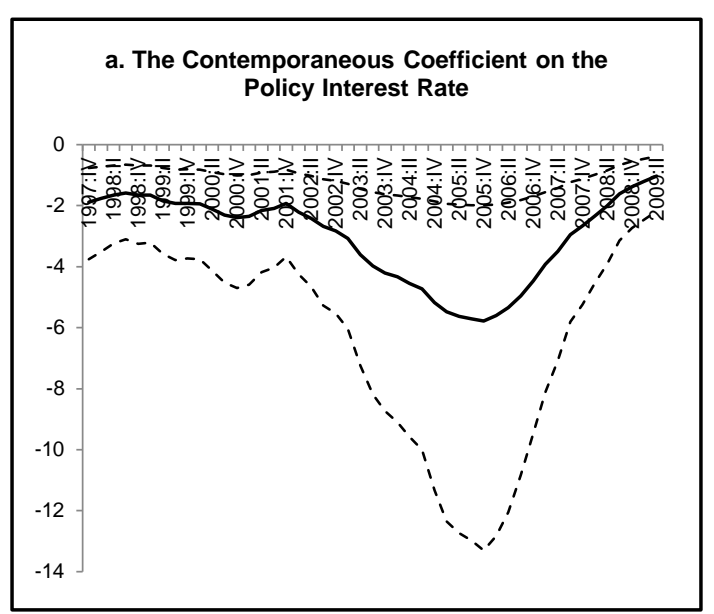

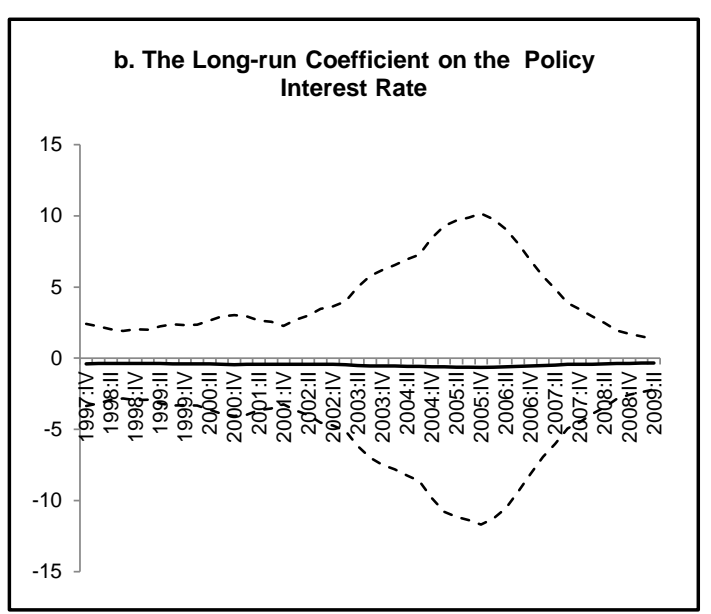

(Data source: authors' analysis)

Then we investigate the impact of monetary policy for the period when the conventional instrument, the short-term interest rate, is used. We distinguish the contemporaneous and longrun impacts by defining:

$$
\zeta_{t}^{\text {Long-run }}=\left(\zeta_{1, t}+\zeta_{2, t}\right) /\left(1-\zeta_{5, t}\right)
$$

where $\zeta_{t}^{\text {Long-run }}$ denotes the long-term coefficient on monetary policy. The results are plotted in Figure $4 \mathrm{a}$ and $4 \mathrm{~b}$. The median posterior distribution of the contemporaneous coefficient $\zeta_{1, t}$ suggests that on average a rise in the policy rate will incur the output growth rate to decrease by $3 \%$. The contemporaneous impact of the interest rate grew prior to the 2008-9 crises hitting the peak around 2005-6 and then decreases because of the cut in the policy interest rate. Consistent with our prior expectations, Figure $4 a$ indicates that traditional monetary stimulus through the interest rate channel is unlikely to work when the policy rate approaches the effective lower bound. This is because its effect on real economic activity would decline dramatically when the rate of interest reaches the lower bound. Furthermore, we obtain the similar findings as presented in Ireland (2007) and 'The Transmission Mechanism of Monetary Policy' (MPC (June 2012)) - a comparison between Figure 4a and 4b suggests that contractionary (expansionary) monetary policy would lower (raise) economic growth but such effects tend to diminish over the long run. 


\section{Conclusions}

Our study investigates the role of expectations in explaining the inflation rate and the real economic growth rate. We assume that there are two types of firms, forward-looking and backward-looking, operating in economy and then theoretically extend the Phillips-IS curve model. We depart from the existing literature such as Gali and Gertler (1999) by hypothesising that both types of firms would consider expectations in setting prices and producing final goods. The difference between them exists in the information set of interest. Forward-looking companies attempt to develop expectation and thus pricing and manufacturing plans based on all information available, while backward-looking ones use past information to make forecasts. To examine our hypothesis and extension to the Phillips-IS model, we apply the UK macro data to our derivation.

The empirical results show that the expectations of both forward-looking and backward-looking firms affect the evolution of inflation and economic activity. However, there is evidence that the use of expectations alone is insufficient to explain the inflation rate and real GDP growth. Consistent with some existing studies such as Rudd and Whelan (2005), we also discover that the inclusion of lagged inflation and output growth in the IS curve and the Phillips curve respectively would improve our modelling and understanding of the current inflation rate and economic development.

\section{References}

Arias, J.E., Rubio-Ramirez, J.F., D.F. Waggoner. (2014), "Inference Based on SVARs Identified with Sign and Zero Restrictions: Theory and Applications", Board of Governors of the Federal Reserve System, International Finance Discussion Papers No. 1100. https://doi.org/10.2139/ssrn.2580264

Ball, L. (1994). "What Determines the Sacrifice Ratio?”, Monetary Policy (Ed.) G. Mankiw, Chicago University Press. https://doi.org/10.3386/w4306

Belongia, M., Ireland, P.N. (2016), "The Evolution of US Monetary Policy: 2000-2017", Journal of Economic Dynamics \& Controls, vol. 73, pp. 78-93. https://doi.org/10.1016/j.jedc.2016.09.009

Calvo, G.A. (1983), "Staggered Prices in a Utility Maximising Framework", Journal of Monetary Economics, vol. 12, no. 3, pp. 383-398. https://doi.org/10.1016/0304-3932(83)90060-0

Chadha, B., Masson, P.R., G. Meredith. (1992), "Models of Inflation and the Cost of Disinflation", International Monetary Fund, vol. 39, no. 2, pp. 395-431. https://doi.org/10.2307/3867064

Friedman, M. (1968), "Inflation: Causes and Consequences", In Dollars and Deficits: Living With America s Economic Problems, pp. 21-71. Englewood Cliffs, NJ: Prentice-Hall.

Gali, J., Gertler, M. (1999), "Inflation Dynamics: A Structural Economic Analysis", Journal of Monetary Economics, vol. 44, no. 2, pp. 195-222. https://doi.org/10.1016/S0304-3932(99)00023-9

Geweke, L. (1992), "Evaluating the Accuracy of Sampling-based Approaches to the Calculation of Posterior Moments", in J.M. Bernardo, J. Berger, A.P. Dawid, A.F.M. Smiths (eds.), Bayesian Statistics, vol. 4, Oxford University Press, Oxford, pp. 169-188 
Goodhart, C., Hofmann, B. (2005a), "The Phillips Curve, the IS Curve and Monetary Transmission: Evidence for the US and the Euro Area", CESiffo Economic Studies, vol. 5, no. 4, pp. 757-775. https://doi.org/10.1093/cesifo/51.4.757

Goodhart, C., Hofmann, B. (2005b), "The IS Curve and the Transmission of Monetary Policy: Is There a Puzzle?", Applied Economics, vol. no. 1, 37, pp. 29-36. https://doi.org/10.1080/0003684042000280355

Inflation Report (August 2009), Available online in PDF at: https://www.bankofengland.co.uk//media/boe/files/inflation-report/2009/august-2009.pdf

Ireland, P.N. (2007), "Changes in the Federal Reserve's Inflation Targets: Causes and Consequences", Journal of Money, Credit and Banking, vol. 39, no. 8, pp. 1851-1882. https://doi.org/10.1111/j.15384616.2007.00091.x

Meenagh, D., Minford, P., Nowell, E., Sofat, P., N. Srinivasan. (2009), "Can the Facts of UK Inflation be Explained by Nominal Rigidity”, Economic Modelling, vol. 29, pp. 978-992. https://doi.org/10.1016/j.econmod.2009.03.004

Monetary Policy Committee. (June 2012), "The Transmission Mechanism of Monetary Policy", Available in PDF at: http://www.bankofengland.co.uk/publications/Documents/other/monetary/montrans.pdf. Last accessed 31st Mar 2014

Nakajima, J. (2011a), "Time-Varying Parameter VAR Model with Stochastic Volatility: An Overview of Methodology and Empirical Applications", Monetary and Economic Studies, vol. 29, pp. 107-142. https://doi.org/10.2202/1935-1690.2323

Nakajima, J. (2011b), "Monetary Policy Transmission under Zero Interest Rates: An Extended TimeVarying Parameter Vector Autoregression Approach", Department of Statistical Science, Duke University Working Paper Series No. 11-08

Nelson, E. (2001), “What Does the UK's Monetary Policy and Inflation Experience Tell US about the Transmission Mechanism?", CEPR Working Paper No. 3047

Primiceri, G.E. (2005), "Time Varying Structural Vector Autoregressions and Monetary Policy", Review of Economic Studies, vol. 72, no. 3, pp. 821-852. https://doi.org/10.1111/j.1467-937X.2005.00353.x

Roberts, J.M. (1995), "New Keynesian Economics and the Phillips Curve", Journal of Money, Credit and Banking, vol. 27, no. 1, pp. 975-984. https://doi.org/10.2307/2077783

Rudd, J., Whelan, K. (2005), "New Tests of the New-Keynesian Phillips Curve", Journal of Monetary Economics, vol. 52, no. 6, pp. 1167-1181. https://doi.org/10.1016/j.jmoneco.2005.08.006

Rudebusch, G., Svensson, L. (1999), “Policy Rules for Inflation Targeting”, Monetary Policy Rules (Ed.) J. Taylor, University of Chicago Press for NBER. https://doi.org/10.3386/w6512

Uhlig, H. (2005), "What Are the Effects of Monetary Policy on Output? Results from an Agnostic Identification Procedure", Journal of Monetary Economics, vol. 51, no. 2, pp. 381-419. https://doi.org/10.1016/j.jmoneco.2004.05.007 